\title{
Levosimendan attenuates multiple organ injury and improves survival in peritonitis-induced septic shock: studies in a rat model
}

\author{
Cheng-Ming Tsao ${ }^{1,2}$, Kai-Yi Li ${ }^{3}$, Shiu-Jen Chen ${ }^{4,5}$, Shuk-Man Ka ${ }^{6}$, Wen-Jinn Liaw ${ }^{2,3,7}$, Hsieh-Chou Huang ${ }^{8,10^{*+}}$ \\ and Chin-Chen $\mathrm{Wu}^{3,9^{*}+}$
}

\begin{abstract}
Introduction: The aim of this study was to investigate the effects of levosimendan on rodent septic shock induced by cecal ligation and puncture (CLP).

Methods: Three hours after peritonitis-induced sepsis, male Wistar rats were randomly assigned to receive an intravenous infusion of levosimendan $(1.2 \mu \mathrm{g} / \mathrm{kg} / \mathrm{min}$ for $10 \mathrm{~min}$ and then $0.3 \mu \mathrm{g} / \mathrm{kg} / \mathrm{min}$ for $6 \mathrm{~h}$ ) or an equivalent volume of saline and vehicle (5\% dextrose) solution.

Results: The levosimendan-treated CLP animals had significantly higher arterial pressure and lower biochemical indices of liver and kidney dysfunction compared to the CLP animals $(P<0.05)$. Plasma interleukin-1 $\beta$, nitric oxide and organ superoxide levels in the levosimendan-treated CLP group were less than those in CLP rats treated with vehicle $(P<0.05)$. In addition, the inducible nitric oxide synthase (iNOS) in lung and caspase-3 expressions in spleen were significantly lower in the levosimendan-treated CLP group $(P<0.05)$. The administration of CLP rats with levosimendan was associated with significantly higher survival (61.9\% vs. $40 \%$ at $18 \mathrm{~h}$ after $C L P, P<0.05)$. At postmortem examination, the histological changes and neutrophil filtration index in liver and lung were significantly attenuated in the levosimendan-treated CLP group (vs. CLP group, $P<0.05$ ).

Conclusions: In this clinically relevant model of septic shock induced by fecal peritonitis, the administration of levosimendan had beneficial effects on haemodynamic variables, liver and kidney dysfunction, and metabolic acidosis.

(1) Lower levels of interleukin-1 $\beta$, nitric oxide and superoxide, (2) attenuation of iNOS and caspase-3 expressions, and

(3) decreases of neutrophil infiltration by levosimendan in peritonitis-induced sepsis animals suggest that anti-inflammation and anti-apoptosis effects of levosimendan contribute to prolonged survival.
\end{abstract}

\section{Introduction}

Despite better understanding of sepsis pathophysiology and improved advanced care in the past decade, the incidence and mortality of sepsis has substantially increased. In the presence of septic shock and associated multiple organ failure, mortality may approach 30 to $40 \%$ [1-3]. Considering that severe sepsis may potentially reduce regional tissue perfusion, the use of vasodilators to open up the microcirculation and improve tissue oxygenation

\footnotetext{
* Correspondence: 85757067huang@gmail.com; ccwu@mail.ndmctsgh.edu.tw ${ }^{\dagger}$ Equal contributors

${ }^{8}$ Department of Anesthesiology, Cheng-Hsin General Hospital, Taipei, Taiwan ${ }^{3}$ Department of Pharmacology, National Defence Medical Centre, Neihu PO Box 90048-504, Taipei 114, Taiwan

Full list of author information is available at the end of the article
}

in sepsis is reasonable [4,5]. Our previous study has also demonstrated that terbutaline, a $\beta_{2}$-adrenoceptor agonist inducing peripheral vasodilation via the cyclic adenosine monophosphate pathway, reduces organ dysfunction and mortality in rats with severe sepsis [6].

The calcium sensitizer, Levosimendan (LS) enhances cardiac contractility independent from the adrenergic system by means of binding to the troponin $\mathrm{C}$ within cardiomyocytes [7]. In addition, LS causes venous, arterial and coronary vasodilation, probably by opening ATPsensitive potassium channels $\left(\mathrm{K}_{\mathrm{ATP}}\right)$ in smooth muscle [8]. Experimental data show that LS improves cardiac performance and organ blood flow during experimental and human septic shock [9-12]. More importantly, both clinical and experimental studies manifest that LS has

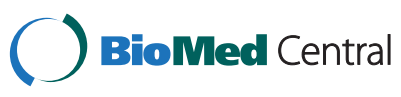


anti-inflammatory and anti-apoptotic properties in addition to its cardiovascular effects [13-15]. In a rat model of severe sepsis induced by cecal ligation and incision, inhaled LS has been found to reduce the releases of plasma IL-1 $\beta$ and IL-6 and expression of splenic caspase-3 [16].

Therefore, we examined the hypothesis that short-term infusion of LS administered after the establishment of peritonitis-induced sepsis would attenuate succeeding organ injury and increase survival in a more clinically relevant model of septic shock. In addition, we investigated the effect of LS on haemodynamics, pro-inflammatory cytokines, free radicals and caspase-3 expression, which may be associated with the organ dysfunction induced by sepsis.

\section{Materials and methods}

All work in this study was approved by the Committee on the Ethics of Animal Experiments of National Defence Medical Centre (permit number IACUC-10-151), and the care and handling of the animals were in adherence to the National Institutes of Health Guidelines for ethical animal treatment. Male adult Wistar rats (280 to 350 g body weight), purchased from the National Laboratory Animal Centre of Taiwan, were kept on a 12-h light/dark cycle at a controlled temperature $\left(21 \pm 2^{\circ} \mathrm{C}\right)$ with free access to food and tap water.

\section{Surgical procedures}

Rats were anaesthetised using intraperitoneal pentobarbital (40 to $50 \mathrm{mg} / \mathrm{kg}$ ) and inhalation of isoflurane $(0.5$ to $1.0 \%)$. Unconscious rats were tested for sufficient depth of anaesthesia by pinching their toes. Polyurethane catheters for blood pressure measurement and drug administration were inserted into left carotid artery and right jugular vein, respectively. Subsequently, the catheters were positioned posteriorly, fixed to the back of the neck. The cannulated animals were allowed to recover to their normal condition overnight with standardised pellet food and tap water ad libitum.

After measurement of baseline haemodynamic analysis and collection of an arterial blood sample, the intraperitoneal sepsis was then induced by cecal ligation and puncture (CLP) using methods described previously [17]. Briefly, a 2-cm-long midline laparotomy was performed under sufficient anaesthesia. The exposed cecum was ligated with a 3-0 silk ligature just distal to the ileocecal valve, punctured twice with an 18-gauge needle. In the sham of control (SOP) group, cecal exposure was performed without any other manipulation. The cecum was then replaced into the abdomen and the abdominal incision was closed. All animals immediately received $0.9 \%$ $\mathrm{NaCl}$ solution (10 mL/kg subcutaneously) for intraoperative fluid loss.
All rats used in the study were kept in the small inhouse animal facility of our institute to enable optimal monitoring: the overall health status was checked every 4 to $6 \mathrm{~h}$ for signs of distress. A subset of rats did not survive $18 \mathrm{~h}$ after induction of sepsis, and specifically, rats were euthanised only at the end of each experiment (at $18 \mathrm{~h}$ after CLP or sham surgery) or upon signs of imminent death (that is, unresponsive to external stimuli, inability to maintain an upright position, tremor and prolonged/deep hypothermia and/or agonal breathing) by using an overdose of pentobarbital $(100 \mathrm{mg} / \mathrm{Kg}$, given intravenously (i.v.)). Then, some tissue specimens of liver and lung were immediately exercised to analyze superoxide levels, western blotting and histological changes. In addition, the survival rate at $18 \mathrm{~h}$ in each group was analysed.

\section{Experimental protocol}

Animals were divided into sham and CLP groups, and then i.v. infused with LS $(1.2 \mu \mathrm{g} / \mathrm{kg} /$ minute for 10 minutes followed by $0.3 \mu \mathrm{g} / \mathrm{kg} /$ minute for $6 \mathrm{~h}$ ), or the same volume of $9 \%$ saline and $5 \%$ dextrose solution in each group at $3 \mathrm{~h}$ after the sham and the CLP operation. LS (Orion Corporation, Espoo, Finland) was dissolved in 5\% dextrose solution and its concentration was $0.01 \mathrm{mg} / \mathrm{mL}$. Each arterial blood sample $(0.8 \mathrm{~mL})$ was collected at baseline (that is, time 0 ) and at specified times (that is, at 3, 9, and $18 \mathrm{~h}$ after CLP or sham surgery). An equal volume of sterile saline was used to immediately replace each volume of withdrawn blood.

\section{Measurement of haemodynamic parameters}

The arterial catheter was connected to a pressure transducer (P23ID, Statham, Oxnard, CA, USA) for the measurement of phasic blood pressure and heart rate, which were displayed on a polygraph recorder (MacLab/4e, AD Instruments Pty Ltd., Castle Hill, Australia). The changes in haemodynamics were recorded at $0,3,9$ and $18 \mathrm{~h}$ after CLP or sham surgery. After recording haemodynamic parameters at each time point, animals were intravenously given a norepinephrine (NE) bolus $(1 \mu \mathrm{g} / \mathrm{kg})$ to examine their vasopressor responses [18-20]. In order to normalise all results of vasopressor responses to their baseline values in all groups, we calculated the values at time 0 of each group as $100 \%$.

\section{Quantification of organ function and injury}

Some arterial blood $(180 \mu \mathrm{L})$ was used to analyse the levels of $\mathrm{pH}$, carbon dioxide tension $\left(\mathrm{PaCO}_{2}\right)$, bicarbonate $\left(\mathrm{HCO}_{3}{ }^{-}\right)$, base excess and potassium concentration by an arterial blood gas analyzer (AVL OPTI Critical Care Analyzer, AVL Scientific Corp., Roswell, GA, USA). Blood glucose was analysed by a One-Touch II blood glucose monitoring system (Lifescan Inc., Milpitas, CA, USA) with 
$10 \mu \mathrm{L}$ of whole blood. The remaining blood was then immediately centrifuged at $7,500 \mathrm{~g}$ for 2 minutes to obtain the plasma. Plasma $(80 \mu \mathrm{L})$ was used to analyse the biochemical parameters of liver and kidney function. Liver function was assessed by measuring plasma levels of aspartate aminotransferase (AST) and alanine aminotransferase (ALT), and renal function was assessed by plasma levels of blood urea nitrogen (BUN) and creatinine. In addition, plasma lactate dehydrogenase (LDH) was measured to evaluate the extent of organ injury. All of these biochemical parameters were analysed by Fuji DRICHEM 3030 (Fuji Photo Film Co., Ltd., Tokyo, Japan).

\section{Measurement of plasma nitric oxide concentrations}

The plasma samples ( $30 \mu \mathrm{L}$ ) were used to measure plasma nitric oxide (NO) concentration, which in the study is actually depicted as the total nitrite and nitrate concentration in plasma. The nitrite/nitrate concentrations in all samples were measured using chemiluminescence, as previously described $[21,22]$. The amounts of nitrate in the plasma were measured by adding a reducing gent $\left(0.8 \% \mathrm{VCl}_{3}\right.$ in $\left.1 \mathrm{~N} \mathrm{HCl}\right)$ to the purge vessel to convert nitrate to $\mathrm{NO}$, which was stripped from the plasma by using helium purge gas. The $\mathrm{NO}$ - was then drawn into a nitric oxide analyzer (Sievers 280 NOA; Sievers Inc., Boulder, CO, USA). Nitrate concentrations were calculated by comparison with standard solutions of sodium nitrate (Sigma Chemical Co., St Louis, MO, USA).

\section{Measurement of plasma IL-1 $\beta$ concentrations}

The plasma samples $(150 \mu \mathrm{L})$ were used to measure the plasma IL-1 $\beta$ in duplicate with an enzyme-linked immunoadsorbent assay kit (R\&D Systems, Inc., Minneapolis, MN, USA) according to the manufacturer's instructions.

\section{Measurement of superoxide production}

Superoxide production was measured by lucigeninenhanced chemiluminescence as previously described $[23,24]$. At the end of study, the animals were exsanguinated and sacrificed with overdose pentobarbital and some tissue specimens were immediately isolated and removed for analysis. The thoracic aorta was carefully trimmed of extravascular tissues and then cut into rings of $5-\mathrm{mm}$ width. The liver, pancreas and spleen tissues $(5 \times 5 \mathrm{~mm})$ were cleared of blood and transferred to scintillation plates. These scintillation plates containing Krebs-Hepes buffer with $1.25 \mathrm{mM}$ lucigenin (final volume of $250 \mu \mathrm{L}$ ) were placed into a microplate luminometer (Hidex Microplate Luminometer, Turku, Finland). Counts were obtained in duplicate for all tissues, which then were dried for $24 \mathrm{~h}$. The results were expressed as counts per sec (in each mg of dry tissue).

\section{Western blot analysis}

After euthanasia, the lung and spleen were obtained and frozen at $-80^{\circ} \mathrm{C}$ before assay. Frozen samples were thawed and homogenised on ice for protein assay (Bio-Rad Laboratories, Hercules, CA, USA), as previously described [17]. For western blotting, supernatants of tissue homogenates $(100 \mu \mathrm{g}$ total protein) were separated on a $10 \%$ (for inducible nitric oxide synthase (iNOS)) and 15\% (for caspase-3) polyacrylamide gel and transferred on to a nitrocellulose membrane (Hoeffer, CA, San Francisco, USA). After blocking for $1.5 \mathrm{~h}$ at room temperature (5\% skimmed milk in Tris-buffered saline containing $0.1 \%$ Tween 20 ), the membrane was incubated overnight $\left(4^{\circ} \mathrm{C}\right)$ with polyclonal anti-mouse iNOS antibody (BD Transduction Laboratories, Lexington, KY, USA) or polyclonal anti-rabbit cleaved caspase 3 antibody (Cell Signaling Technology, Danvers, CO, USA) at a 1:1,000 dilution in blocking buffer followed by a horseradishperoxidase-coupled secondary antibody (BD Transduction Laboratory) for $1 \mathrm{~h}$ at room temperature at a 1:5,000 dilution for iNOS and 1:3,000 for caspase- 3 . The immunoreactive proteins were visualised with the enhanced peroxidase/luminol chemiluminescence reaction kit (Amersham Pharmacia Biotech, Little Chalfont, UK) followed by exposure to radiographic film. The blots were then stripped and incubated with anti- $\beta$-actin antibody (diluted 1:3,000; BD Transduction Laboratory) to ensure equal loading. The ratios of the bands are shown.

\section{Histological assessment}

Specimens of lung, liver and spleen were harvested and immediately fixed in 10\% formaldehyde for more than $24 \mathrm{~h}$. The fixed tissues were dehydrated in graded ethanol and embedded in paraffin. Each paraffin block was processed into $4 \mu \mathrm{m}$-thick slices that were stained with hematoxylin and eosin. This histological alteration was quantitatively analysed as indexes of the severity of polymorphonuclear neutrophil (PMN) infiltration and apoptosis in three animals from each group. Apoptotic cells were identified by the characteristic morphology of nuclear fragmentation (karyorrhexis) and cell shrinkage with condensed nuclei (pyknosis) [25]. The indexes were scored 0 (minimal) to 4 (maximal), determined by counting the numbers of PMN and apoptotic cells in 10 randomly selected high-power fields evaluated by a pathologist in a blinded fashion.

\section{Statistical analysis}

The data are presented as mean \pm standard error of the mean (SEM) of $n$ determinations, where $n$ represents the number of animals studied. The significance of differences in the measured values between groups was analysed using one-way analysis of variance (ANOVA) or two-way (time and group) ANOVA for repeated measures, followed by 
Bonferroni correction as a post hoc test. The scores for neutrophil infiltration and apoptosis were compared by the Mann-Whitney $U$-test. The chi-square test was used to evaluate the effect of treatment on survival rates. A $P$-value $<0.05$ was considered to be statistically significant.

\section{Results}

\section{Systemic haemodynamic parameters}

The baseline values of the haemodynamic parameters were comparable in all groups as shown in Table 1. CLP led to a significantly substantial attenuation in systolic blood pressure, diastolic blood pressure and pulse pressure at $18 \mathrm{~h}(\mathrm{P}<0.05$, versus the SOP group), and there was no significant difference between CLP and CLP + vehicle (Veh) groups. The treatment of CLP rats with LS significantly prevented severe hypotension and increased pulse pressure at $18 \mathrm{~h}(\mathrm{P}<0.05$, versus CLP + Veh). In addition, the SOP rats treated with LS had significantly increased pulse pressure at $18 \mathrm{~h}$ compared to the SOP rats treated with saline.

CLP led to a significant and sustained increase in heart rate at 3 to $18 \mathrm{~h}$ after CLP ( $P<0.05$, versus SOP group; Table 1), and there was no difference between CLP and CLP + Veh groups. The treatment of CLP rats with LS significantly prevented the CLP-induced tachycardia at
$18 \mathrm{~h}(\mathrm{P}<0.05$, versus CLP + Veh). The SOP rats treated with saline or LS exhibited stable haemodynamic conditions during the experimental period and there was no significant difference among groups.

CLP led to a significantly substantial attenuation in pressor responses to norepinephrine at $18 \mathrm{~h}(P<0.05$, versus SOP group; Table 1), and there was no significant difference between the CLP and the CLP + Veh groups. However, LS administration significantly prevented the decrease of pressor responses to norepinephrine in the CLP group at $18 \mathrm{~h}$. The SOP group treated with saline or LS exhibited stable haemodynamic conditions during the experimental period and there was no significant difference among groups.

\section{Organ injury/dysfunction}

Baseline values of plasma markers of biochemical parameters were not significantly different among groups (Figure 1). No significant changes in these parameters were observed during the experimental period in the SOP group treated with saline or LS, and there was no significant difference between the CLP and the CLP + Veh groups.

Significant increases in plasma levels of ALT, AST, $\mathrm{LDH}$ and creatinine at $18 \mathrm{~h}$, and BUN at 9 and $18 \mathrm{~h}$

Table 1 Changes in haemodynamic parameters

\begin{tabular}{|c|c|c|c|c|c|c|}
\hline Variables & Time point & SOP $(n=10)$ & $S O P+$ LS $(n=6)$ & CLP $(n=10)$ & CLP + Veh $(n=6)$ & $C L P+\operatorname{LS} \quad(n=10)$ \\
\hline \multirow[t]{4}{*}{ Heart rate, beats/minute } & $\mathrm{Oh}$ & $388 \pm 12$ & $367 \pm 13$ & $334 \pm 7$ & $350 \pm 15$ & $369 \pm 8$ \\
\hline & $3 \mathrm{~h}$ & $413 \pm 12$ & $392 \pm 16$ & $444 \pm 11^{*}$ & $461 \pm 12^{*}$ & $474 \pm 12^{*}$ \\
\hline & $9 \mathrm{~h}$ & $395 \pm 10$ & $382 \pm 16$ & $472 \pm 11^{*}$ & $488 \pm 20^{*}$ & $518 \pm 13^{*}$ \\
\hline & $18 \mathrm{~h}$ & $388 \pm 11$ & $404 \pm 20$ & $492 \pm 17^{*}$ & $499 \pm 14^{*}$ & $478 \pm 8^{*}+$ \\
\hline \multirow[t]{4}{*}{ Systolic pressure, mmHg } & $\mathrm{Oh}$ & $140.3 \pm 2.1$ & $141.4 \pm 3.3$ & $133.7 \pm 2.6$ & $147 \pm 4.9$ & $139 \pm 2.9$ \\
\hline & $3 \mathrm{~h}$ & $146.6 \pm 2.6$ & $144.8 \pm 1$ & $139.8 \pm 2.7$ & $146.8 \pm 6.1$ & $141.8 \pm 2.6$ \\
\hline & $9 \mathrm{~h}$ & $148.1 \pm 2.9$ & $142.7 \pm 1.9$ & $124.7 \pm 2.6^{*}$ & $130 \pm 6.8$ & $133.8 \pm 3.4$ \\
\hline & $18 \mathrm{~h}$ & $140.4 \pm 3.2$ & $146 \pm 2.3$ & $87.4 \pm 5.1^{*}$ & $88 \pm 5.1^{*}$ & $126.7 \pm 4.1 \dagger$ \\
\hline \multirow[t]{4}{*}{ Diastolic pressure, mmHg } & $\mathrm{Oh}$ & $106.5 \pm 2.6$ & $103.9 \pm 3.3$ & $99.8 \pm 2.4$ & $111.9 \pm 3.9$ & $104.2 \pm 2.5$ \\
\hline & $3 \mathrm{~h}$ & $112.5 \pm 2.3$ & $108.2 \pm 2.2$ & $109.9 \pm 2.5$ & $118.4 \pm 6.6$ & $112.3 \pm 2.7$ \\
\hline & $9 \mathrm{~h}$ & $112.6 \pm 3.5$ & $104.6 \pm 3$ & $102.7 \pm 2.6^{*}$ & $108.3 \pm 5.8$ & $96 \pm 3.5$ \\
\hline & $18 \mathrm{~h}$ & $105.8 \pm 3.6$ & $100.3 \pm 4.4$ & $66.7 \pm 4^{*}$ & $69.5 \pm 3.8^{*}$ & $83.8 \pm 4.3^{*}+$ \\
\hline \multirow[t]{4}{*}{ Pulse pressure, $\mathrm{mmHg}$} & $\mathrm{Oh}$ & $33.8 \pm 0.9$ & $37.5 \pm 1.5$ & $33.9 \pm 1.1$ & $35.1 \pm 2.4$ & $35.3 \pm 0.9$ \\
\hline & $3 \mathrm{~h}$ & $34.1 \pm 0.9$ & $36.7 \pm 1.6$ & $30 \pm 1.3$ & $28.2 \pm 2.3$ & $29.5 \pm 0.8$ \\
\hline & $9 \mathrm{~h}$ & $35.5 \pm 0.7$ & $38.1 \pm 2.2$ & $22 \pm 1^{*}$ & $21.6 \pm 2^{*}$ & $37.9 \pm 2.7 \dagger$ \\
\hline & $18 \mathrm{~h}$ & $34.6 \pm 0.9$ & $45.7 \pm 2.9^{*}$ & $20.7 \pm 1.8^{*}$ & $18.6 \pm 2.6^{*}$ & $42.9 \pm 1.9^{*}+$ \\
\hline \multirow[t]{4}{*}{ Pressor response to norepinephrine, \% } & $\mathrm{Oh}$ & $100 \pm 0$ & $100 \pm 0$ & $100 \pm 0$ & $100 \pm 0$ & $100 \pm 0$ \\
\hline & $3 \mathrm{~h}$ & $90.8 \pm 4.1$ & $94.5 \pm 4$ & $40.8 \pm 5.2^{*}$ & $31.1 \pm 3.1^{*}$ & $33.4 \pm 3.3^{*}$ \\
\hline & $9 \mathrm{~h}$ & $105 \pm 3$ & $96.4 \pm 5.4$ & $33.7 \pm 3.1^{*}$ & $29.1 \pm 2.5^{*}$ & $33.9 \pm 2.8^{*}$ \\
\hline & $18 \mathrm{~h}$ & $103 \pm 3.2$ & $94.7 \pm 2.6$ & $21.9 \pm 1.8^{*}$ & $19.5 \pm 1.2^{*}$ & $31.1 \pm 1.5^{*}+$ \\
\hline
\end{tabular}

Depicted are changes in different groups of SOP $(n=10)$, SOP + LS $(n=6), C L P(n=10), C L P+$ Veh $(n=6)$ and CLP + LS $(n=12)$. Data are expressed as mean \pm standard error of the mean. ${ }^{*} P<0.05$, all groups versus $S O P ;{ }^{\dagger} P<0.05, C L P+L S$ versus $C L P+V e h . C L P$, cecal ligation and puncture; $L S$, Levosimendan; SOP, sham of operation; Veh: vehicle (5\% dextrose solution). 

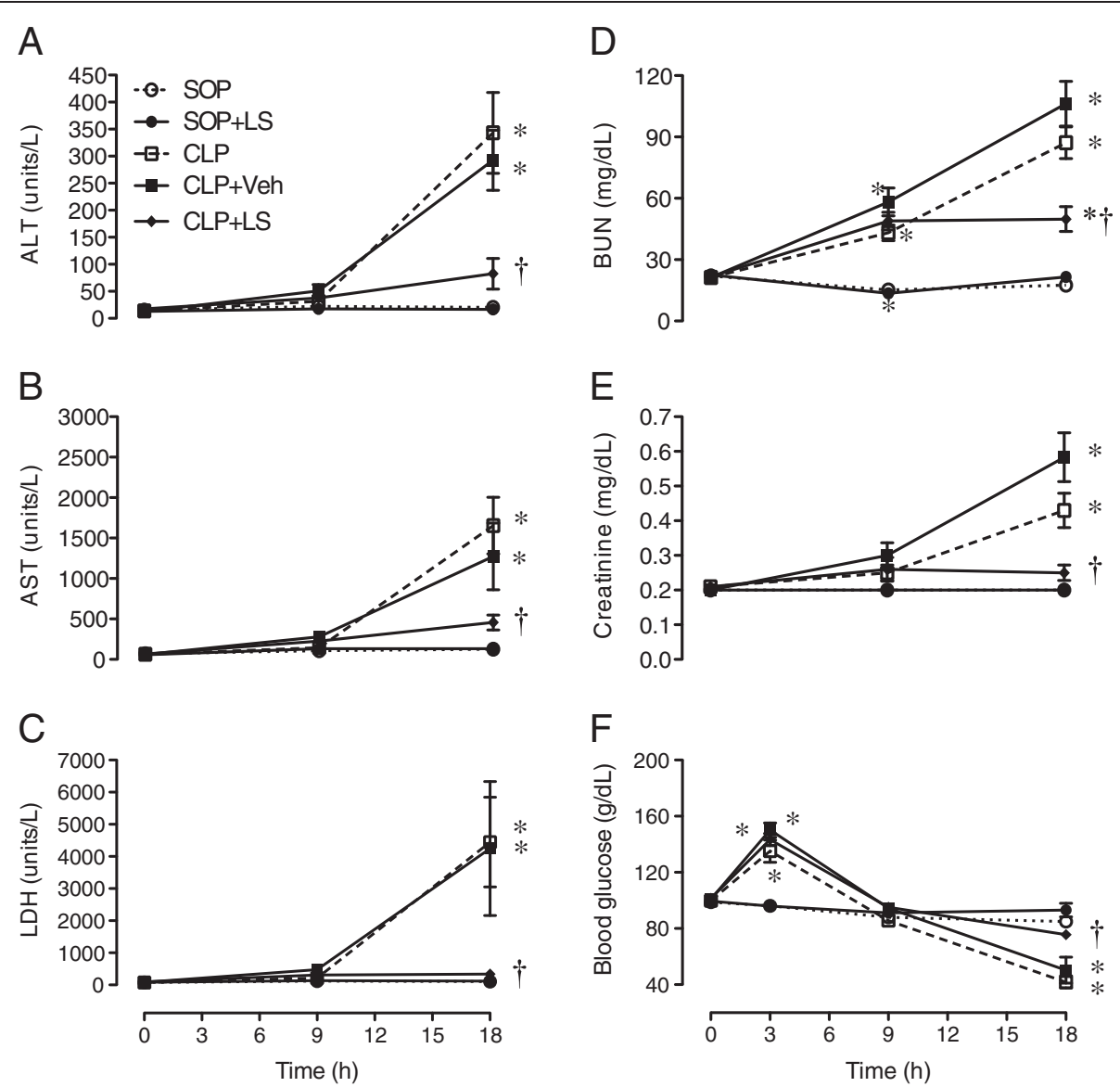

Figure 1 Progress of plasma (A) alanine aminotransferase (ALT), (B) aspartate aminotransferase (AST), (C) lactate dehydrogenase (LDH), (D) blood urea nitrogen (BUN), (E) creatinine, and (F) blood glucose during the experimental period. Depicted are the changes in plasma biochemical parameters in different groups of sham operation (SOP, $n=10)$, SOP plus levosimendan administration $(S O P+L S, n=6)$, cecal ligation and puncture (CLP, $n=10)$, CLP plus vehicle treatment $(C L P+V e h, n=6)$ and CLP plus levosimendan administration $(C L P+L S, n=12)$. Data are expressed as mean \pm standard error of the mean. ${ }^{*} P<0.05$, all groups versus $S O P .{ }^{\dagger} P<0.05, C L P+L S$ versus $C L P+V e h$.

were found after CLP compared to the SOP group $(P<0.05$, Figure $1 \mathrm{~A}-\mathrm{C}$ and $\mathrm{E})$. The rises in plasma AST, ALT, LDH, BUN and creatinine levels at $18 \mathrm{~h}$ after CLP were attenuated by LS $(P<0.05$ versus CLP + Veh).

The CLP surgery induced a biphasic change in blood glucose, that is, hyperglycemia at the early stage $(3 \mathrm{~h})$ and hypoglycemia at the late stage $(18 \mathrm{~h})(P<0.05$ versus SOP group; Figure 1F). However, the treatment of CLP rats with LS significantly ameliorated the hypoglycemia at $18 \mathrm{~h}(P<0.05$, versus $C L P+V e h)$, yet the level was below the baseline and the SOP values.

Blood gas parameters and blood potassium concentration There was no statistical difference in blood gas parameters in SOP rats, and there was no statistical difference in blood $\mathrm{pH}$ level among groups during the experimental period (Table 2). However, the rats treated with CLP for $18 \mathrm{~h}$ had significant decreases in $\mathrm{PaCO}_{2}, \mathrm{HCO}_{3}{ }^{-}$and base excess at 9 and $18 \mathrm{~h}(P<0.05$, versus SOP group; Table 2$)$, indicating respiratory compensation for metabolic acidosis.
The compensated metabolic acidosis induced by CLP at $18 \mathrm{~h}$ was ameliorated by the treatment with $\mathrm{LS}(P<0.05$, versus CLP + Veh; Table 2). However, there was no significant difference between CLP and CLP + Veh groups.

There was no significant difference in blood potassium concentration in the SOP rats (Table 2). However, the rats treated with CLP for $18 \mathrm{~h}$ had significant increases in potassium concentration at $18 \mathrm{~h}(P<0.05$, versus the SOP group; Table 2), and there was no significant difference between the CLP and the CLP + Veh groups. The hyperkalemia induced by CLP at $18 \mathrm{~h}$ was ameliorated by the treatment with $\operatorname{LS}(P<0.05$ versus $C L P+V e h$; Table 2).

\section{Plasma nitrite/nitrate levels}

The basal plasma level of nitrite/nitrate was not significantly different among groups (Figure 2A). The CLP surgery led to a significant increase in plasma nitrite/nitrate level ( $P<0.05$ versus the SOP group), which reached a plateau at $9 \mathrm{~h}$, and there was no difference between the 
Table 2 Changes in blood gas parameters and potassium concentration

\begin{tabular}{|c|c|c|c|c|c|c|}
\hline Variables & Group & SOP & SOP + LS & CLP & CLP + Veh & $\mathrm{CLP}+\mathrm{LS}$ \\
\hline \multirow[t]{3}{*}{$\mathrm{pH}$} & $\mathrm{Oh}$ & $7.6 \pm 0.01$ & $7.5 \pm 0.01$ & $7.6 \pm 0.02$ & $7.6 \pm 0.01$ & $7.6 \pm 0.01$ \\
\hline & $9 \mathrm{~h}$ & $7.5 \pm 0.01$ & $7.5 \pm 0.01$ & $7.6 \pm 0.01$ & $7.6 \pm 0.02$ & $7.6 \pm 0.02$ \\
\hline & $18 \mathrm{~h}$ & $7.6 \pm 0.01$ & $7.6 \pm 0.01$ & $7.5 \pm 0.01$ & $7.5 \pm 0.03$ & $7.6 \pm 0.01$ \\
\hline \multirow[t]{3}{*}{$\mathrm{PaCO}_{2}, \mathrm{mmHg}$} & $\mathrm{Oh}$ & $34 \pm 1.7$ & $37 \pm 2.3$ & $32 \pm 1.7$ & $34 \pm 0.4$ & $35 \pm 0.7$ \\
\hline & $9 \mathrm{~h}$ & $36 \pm 1$ & $37 \pm 1.8$ & $22 \pm 0.9^{*}$ & $24 \pm 1.4^{*}$ & $24 \pm 1.7^{*}$ \\
\hline & $18 \mathrm{~h}$ & $31 \pm 1.2$ & $32 \pm 1.4$ & $20 \pm 1.3^{*}$ & $21 \pm 1.9^{*}$ & $28 \pm 1.4 \dagger$ \\
\hline \multirow[t]{3}{*}{$\mathrm{HCO}_{3}{ }^{-}, \mathrm{mM}$} & $\mathrm{Oh}$ & $30 \pm 0.7$ & $31.1 \pm 1.1$ & $27.9 \pm 0.9$ & $30 \pm 0.7$ & $29.9 \pm 0.6$ \\
\hline & $9 \mathrm{~h}$ & $29.4 \pm 0.6$ & $29.4 \pm 1.1$ & $20.8 \pm 0.8^{*}$ & $22.1 \pm 1.1^{*}$ & $23.2 \pm 0.8^{*}$ \\
\hline & $18 \mathrm{~h}$ & $27.6 \pm 0.7$ & $28.5 \pm 1.4$ & $16.7 \pm 1^{*}$ & $15.4 \pm 1.2^{*}$ & $24.5 \pm 1 \dagger$ \\
\hline \multirow[t]{3}{*}{ Base excess, mM } & $\mathrm{Oh}$ & $7.8 \pm 0.5$ & $8.4 \pm 0.7$ & $7.3 \pm 0.2$ & $7.9 \pm 0.8$ & $7.5 \pm 0.5$ \\
\hline & $9 \mathrm{~h}$ & $6.7 \pm 0.5$ & $6.7 \pm 0.7$ & $1.2 \pm 0.7^{*}$ & $2.2 \pm 1.1^{*}$ & $3.6 \pm 0.5^{*}$ \\
\hline & $18 \mathrm{~h}$ & $5.4 \pm 0.5$ & $6.7 \pm 1.1$ & $-3.2 \pm 0.8^{*}$ & $-5.5 \pm 1.3^{*}$ & $3.2 \pm 0.9^{*}+$ \\
\hline \multirow[t]{3}{*}{ Potassium, mM } & $\mathrm{Oh}$ & $3.7 \pm 0.1$ & $3.9 \pm 0.1$ & $3.8 \pm 0.1$ & $3.8 \pm 0.1$ & $3.9 \pm 0.1$ \\
\hline & $9 \mathrm{~h}$ & $3.6 \pm 0.1$ & $4 \pm 0.1$ & $3.9 \pm 0.1$ & $3.9 \pm 0.2$ & $3.9 \pm 0.1$ \\
\hline & $18 \mathrm{~h}$ & $3.6 \pm 0.1$ & $3.7 \pm 0.2$ & $4.9 \pm 0.2^{*}$ & $5.2 \pm 0.4^{*}$ & $3.8 \pm 0.1 \dagger$ \\
\hline
\end{tabular}

Depicted are the changes in different groups of SOP $(n=10)$, SOP + LS $(n=6), C L P(n=10), C L P+$ Veh $(n=6)$ and CLP + LS ( $n=12)$. Data are expressed as mean \pm standard error of the mean. ${ }^{*} P<0.05$ all groups versus SOP; ${ }^{\dagger} P<0.05, \mathrm{CLP}+\mathrm{LS}$ versus CLP + Veh. CLP: cecal ligation and puncture; $\mathrm{LS}$ : Levosimendan; SOP: sham of operation; Veh: vehicle (5\% dextrose solution).

CLP and the CLP + Veh groups. The treatment of CLP rats with LS significantly inhibited the CLP-induced increase in plasma nitrite/nitrate level at 9 and $18 \mathrm{~h}(P<0.05$ versus CLP + Veh). In the SOP group, no significant increase in plasma nitrite/nitrate levels was detectable during the experimental period. The treatment of SOP rats with LS alone had no significant effect on plasma level of nitrite/nitrate.

\section{Plasma IL-1 $\beta$ Levels}

The basal plasma level of IL-1 $\beta$ was not significantly different between any of the experimental groups studied (Figure 2B). The CLP surgery led to significant increases in plasma IL-1 $\beta$ levels, and reached a peak at $18 \mathrm{~h}(P<0.05$ versus the SOP group), and there was no significant difference between the CLP and the CLP + Veh groups. The treatment of CLP rats with LS significantly inhibited the CLP-induced increases in plasma IL-1 $\beta$ levels at $18 \mathrm{~h}$ $(P<0.05$ versus CLP + Veh $)$. In the SOP group, no significant increases in plasma IL-1 $\beta$ levels were detectable during the experimental period. The treatment of SOP rats with LS alone, however, had no significant effect on plasma level of IL-1 $\beta$.

\section{Organ superoxide levels}

The basal production of superoxide was detectable in aorta, liver, spleen and pancreas in SOP rats at the end of the experiment (Figure 3). A significant increase in the superoxide levels of these organs was observed in CLP rats $(P<0.05$ versus the SOP group), and there was no significant difference between the CLP and the CLP + Veh groups. However, the treatment of CLP rats with LS significantly inhibited the production of superoxide $(P<0.05$ versus CLP + Veh), whereas LS itself had no significant effect on the change of superoxide level in SOP rats.

\section{iNOS protein and caspase-3 expression}

The protein expression of iNOS protein was undetectable in lung homogenates obtained from both SOP rats (Figure 4A). A significant induction of iNOS protein was observed in lung homogenates from the CLP rats $(P<0.05$ versus the SOP group), and there was no significant difference between CLP and CLP + Veh groups. The treatment of CLP rats with LS significantly reduced the expression of iNOS protein in the lung $(P<0.05$ versus CLP + Veh).

The protein expression of cleaved caspase- 3 protein was undetectable in spleen homogenates obtained from both SOP rats (Figure 4B). A significant induction of cleaved caspase-3 protein was observed in spleen homogenates from the CLP rats $(P<0.01$ versus the SOP group), and there was no significant difference between the CLP and the CLP + Veh groups. The treatment of CLP rats with LS significantly reduced the expression of cleaved caspase- 3 protein in the spleen $(P<0.05$ versus CLP + Veh).

\section{Histological studies}

At the end of the study, stained specimens from CLP rats revealed 1) increased interstitial edema and decreased alveolar spaces in the lung, and 2) increased 

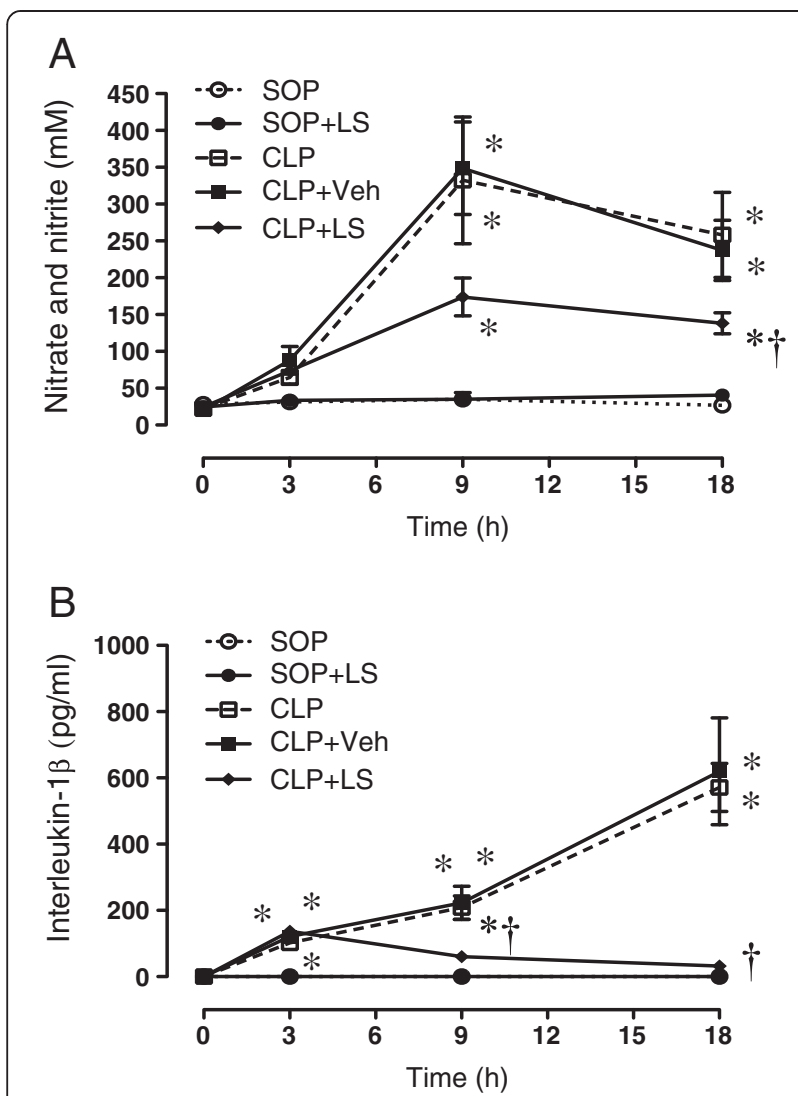

Figure 2 Progress of plasma (A) nitric oxide (NO) and (B) interleukin-1 $\beta$ (IL-1 $\beta$ ) levels during the experimental period. Depicted are the changes of plasma NO and IL-1 $\beta$ levels in different groups of sham operation (SOP, $n=10$ ), SOP plus Levosimendan administration ( $S O P+L S, n=6$ ), cecal ligation and puncture (CLP, $n=10), C L P$ plus vehicle treatment (CLP + Veh, $n=6)$ and CLP plus Levosimendan administration $(C L P+L S, n=12)$. Data are expressed as mean \pm standard error of the mean. ${ }^{*} P<0.05$, all groups versus SOP; ${ }^{\dagger} P<0.05, \mathrm{CLP}+\mathrm{LS}$ versus $\mathrm{CLP}+$ Veh.

interstitial edema and marked necrosis in the liver compared to those from the SOP group (Figure 5). However, the histopathological changes in these organs were improved after LS treatment. Light microscopy only showed a little infiltration or sequestration of PMNs in lung and liver from the SOP group, whereas overt infiltration of PMNs in these tissues was observed in CLP rats $(.0 \pm 0.6$ in lung and $2.0 \pm 0.6$ in liver; $P<0.05)$. There was no significant difference between the CLP and the CLP + Veh groups. However, in CLP rats treated with LS, the PMN infiltrations were significantly reduced $(1.7 \pm 0.3$ in lung, and 0.0 in liver; $P<0.05$ versus CLP). In addition, light microscopy showed no apoptosis in the spleen from SOP rats (Figure 6), whereas severe apoptosis were found in this organ from CLP rats $(3.7 \pm 0.3$ in spleen; $P<0.05)$. However, the apoptosis index was significantly reduced in CLP rats treated with LS $(2 \pm 0 ; P<0.05$ versus CLP).

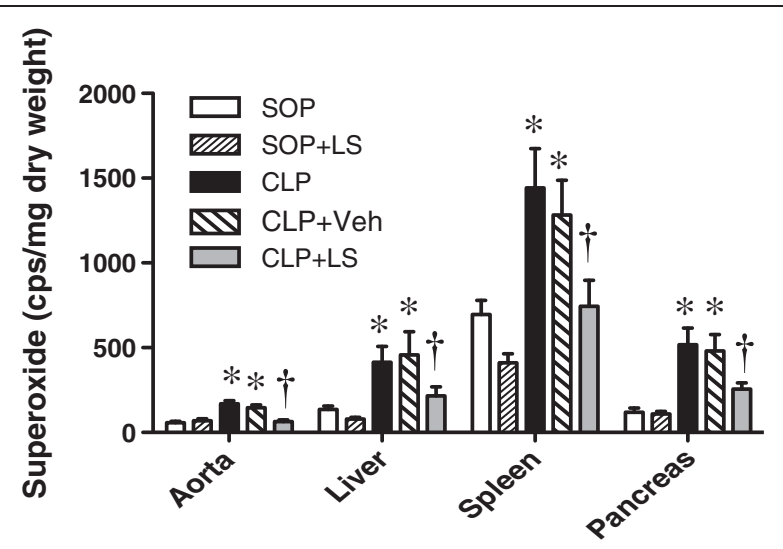

Figure 3 Superoxide levels of aorta, liver, spleen and pancreas at $18 \mathrm{~h}$ after surgery. Depicted are the changes in different groups of sham operation (SOP, $n=10$ ), SOP plus Levosimendan administration $(S O P+L S, n=6)$, cecal ligation and puncture (CLP, $n=10), C L P$ plus vehicle treatment (CLP + Veh, $n=6$ ) and CLP plus Levosimendan administration (CLP $+L S, n=12)$. Data are expressed as mean \pm standard error of the mean. ${ }^{*} P<0.05$, all groups versus $S O P,{ }^{\dagger} P<0.05, C L P+L S$ versus CLP + Veh.

\section{Survival rate}

No mortality was observed within $18 \mathrm{~h}$ in the SOP rats (survival rate $=100 \%$ ). The 9 -h and 18 -h survival rates of CLP animals were $64 \%$ (that is, 16/25 animals) and 40\% (that is, 10/25 animals), respectively (Table 3 ), while the 9-h and 18-h survival rates of CLP + Veh animals were 64.7 (that is, $11 / 17$ animals) and $41.1 \%$ (that is, $7 / 17$ animals), respectively. There was no significant difference in survival rate between CLP and CLP + Veh groups. In contrast, the rats treated with LS had higher survival rates of $71.4 \%$ (that is, $15 / 21$ animals) at $9 \mathrm{~h}$ and $61.9 \%$ (that is, $13 / 21$ animals) at $18 \mathrm{~h}$ after CLP. Thus, LS significantly increased the 18 -h survival rate of CLP rats $(P<0.05$ versus CLP + Veh $)$. Because of clots or kinking of the arterial catheter, blood and data could not be collected in some of rats in each group that survived the full $18 \mathrm{~h}$ of the experiment.

\section{Discussion}

The major findings are that an intravenous infusion of LS: 1) increased arterial blood pressure and pressor response to the NE, 2) reduced plasma levels of biochemical parameters, 3) attenuated metabolic acidosis, and 4) prevented histopathological changes in CLP-treated rats. This study demonstrated that the LS application improved survival in sepsis as a consequence of reducing multiple organ injury. In addition, LS acted by inhibiting plasma IL-1 $\beta$ and NO production, attenuating superoxide formation, and suppressing iNOS and cleaved caspase-3 expression.

Clinically, LS is dissolved in a glucose $5 \%$ solution and administered preferably by continuous intravenous infusion. 


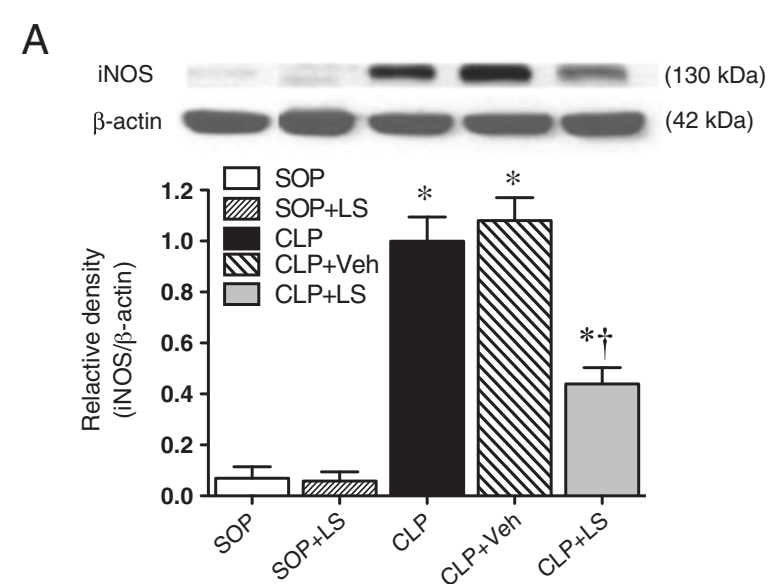

B

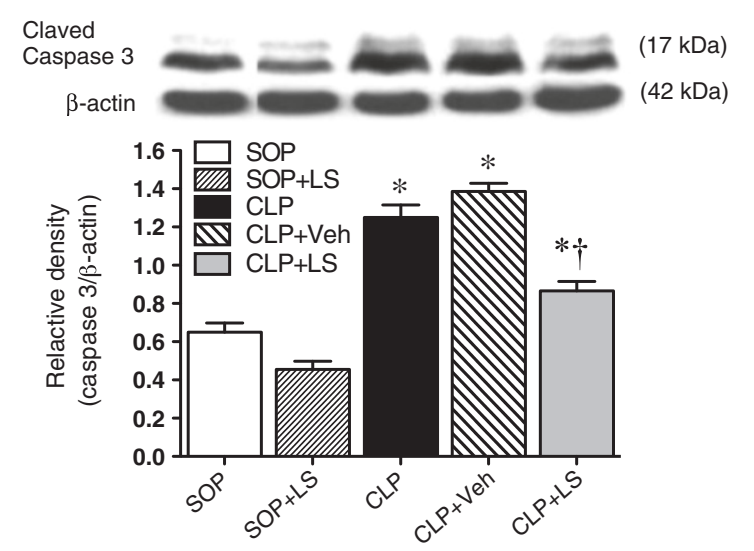

Figure 4 Expressions of (A) lung inducible nitric oxide (NO) synthase (iNOS) and (B) spleen-cleaved caspase 3. Depicted are the expressions of lung iNOS and spleen-cleaved caspase 3 at the end of the study in different groups of sham operation (SOP, $n=3)$, SOP plus Levosimendan administration ( $S O P+L S, n=3)$, cecal ligation and puncture (CLP, $n=5), C L P$ plus vehicle treatment (CLP + Veh, $n=5)$ and CLP plus Levosimendan administration $(C L P+L S, n=5)$. Data are expressed as mean \pm standard error of the mean. ${ }^{*} P<0.05$, all groups versus SOP, ${ }^{\dagger} P<0.05, \mathrm{CLP}+\mathrm{LS}$ versus $\mathrm{CLP}+$ Veh.

An interesting observation in the present study was the fact that 6-h infusion of LS administered $3 \mathrm{~h}$ later after CLP procedure had the capability of improving survival at the end of the 18-h experiment, while the infusion of vehicle (that is, $5 \%$ dextrose in this study) did not change the survival of CLP-treated rats. Furthermore, Scheiermann et al. found that a single dose of intravenous LS could prolong survival for more than $3 \mathrm{~h}$ after the onset of sepsis [16]. The elimination half-life of LS is approximately $1 \mathrm{~h}$, however, the active LS metabolite OR-1896 has a longer half-life of 75 to $80 \mathrm{~h}$ [26]. Thus, OR-1896 may also potentially account for the protective effects of LS in our study.

The animal model of CLP developed hypotension and tachycardia as typically seen in human septic shock $[27,28]$. In the present study, the infusion of LS increased pulse pressure in sham- and CLP-treated rats, suggesting this is due to its positive inotropic effects. Vasodilation induced by activation of the $\mathrm{K}_{\mathrm{ATP}}$ channel is another major property of LS. However, the LS dosage used in our study did significantly raise diastolic blood pressure but did not aggravate hypotension induced by CLP. Thus, this may be due to a positive inotropic effect outweighing the vasodilating component of LS. The administration of CLP rats with LS also attenuated sepsis-induced hypo-reactivity to NE possibly, due to its increasing effect on calcium sensitisation. It has been shown that sepsis-induced hypo-reactivity to norepinephrine is associated with NO-derived peroxynitrite [29-31]. Therefore, LS-decreased plasma NO levels in sepsis may also contribute to the improvement of vascular dysfunction.

There is increasing evidence that the apoptotic mode of cell death in critically ill patients plays a pivotal role in the pathogenesis of the sepsis syndrome [32,33]. Apoptotic cell death can be induced by caspase- 3 through the extrinsic death-receptor and intrinsic mitochondria pathway, which can be activated by diverse stimuli, including proinflammatory cytokines, reactive oxygen species and $\mathrm{NO}$ $[34,35]$. Together with increased amounts of NO that are produced by the iNOS, superoxide forms the highly reactive peroxynitrite that causes irreversible damage to proteins, causing mitochondrial dysfunction and organ failure [32]. Our present study demonstrated that IL-1 $\beta, \mathrm{NO}$ and superoxide production and iNOS expression were increased in CLP-induced septic rats, which were attenuated by LS administration. Furthermore, decreased apoptosis, as determined by the cleaved caspase- 3 protein expression, was observed in the spleen of the CLP + LS group compared to the CLP + Veh group, indicating LS has an anti-apoptosis effect in the spleen [36].

Furthermore, LS administration decreased the inflammatory infiltration by neutrophils in vital organs such as liver and lung. Such neutrophil infiltration can lead to vascular dysfunction as well as parenchymal cell injury [37]. This indicates that LS could prevent organ injury in sepsis by its antioxidant and anti-inflammatory properties. Torraco et al. also reveal that LS protects mitochondria from the oxidative stress in patients suffering with septic shock [38]. These results suggest that beneficial effects of LS administration on biomarkers of oxidative stress, inflammation, tissue injury, and apoptosis were further strengthened by the favorable outcome in the study group, that is, LS-treated CLP animals had about $22 \%$ survival benefit over CLP controls.

On the other hand, splanchnic hypoperfusion and subsequent mucosal ischaemia result in increased inflammation, gut permeability and bacterial translocation, further exacerbating multiple organ dysfunction induced by sepsis [39]. In addition, hepatic and renal dysfunction may lead to the systemic release of inflammatory toxins, which 


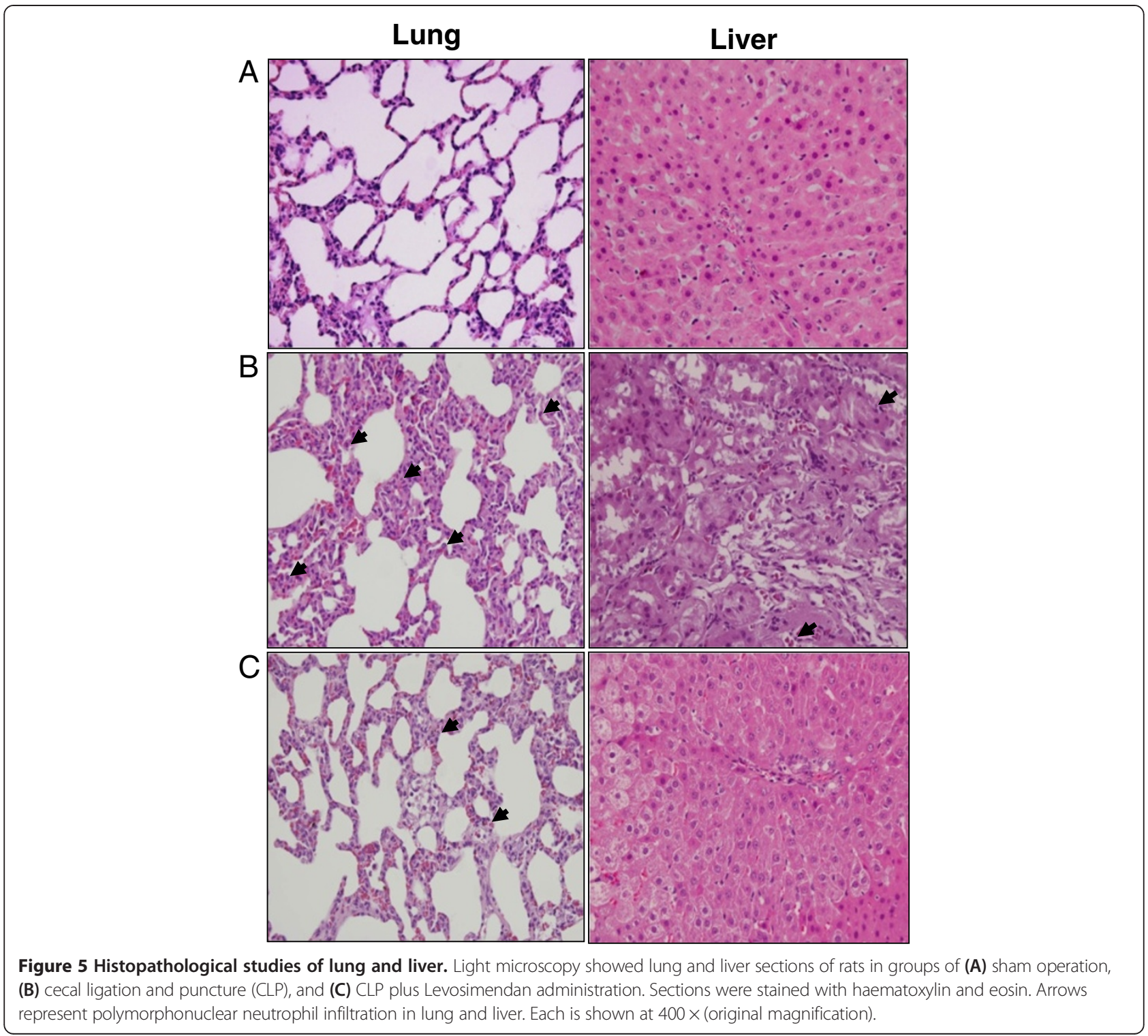

further worsen tissue injury. Much importance has recently been attributed to tissue oxygenation in sepsis, and it has been suggested that vasodilators could be used therapeutically to increase the microcirculation and improve tissue oxygenation [40,41]. Earlier studies demonstrate that LS increases sublingual oxygenation and splanchnic perfusion during clinical septic shock $[10,42]$. In addition, LS increases portal blood flow, intestinal mucosal oxygenation and vascular reactivity in a porcine model of sepsis, whereas AST is not significantly attenuated [12]. However, biochemical parameters of liver and renal injury and metabolic acidosis were attenuated after LS treatment in our present study. Furthermore, light microscopy showed that the histopathological changes in these tissues were also improved. It is assumed to be associated with opening of the mitochondria $\mathrm{K}_{\mathrm{ATP}}$ channel, increasing perfusion of peripheral tissues and decreasing organ injury $[43,44]$.

The current study has some limitations that need to be addressed. First, it was conducted in previously healthy animals under highly controlled circumstances, in contrast to the clinical setting in which patients often have underlying illness and co-morbidities. Second, we did not use antibiotics in order to avoid any influence of LS on the organ function in this study. Moreover, only one single intravenous dose of continuous LS infusion was used, and consequently, we cannot exclude the possibility that a larger dose could yield better histological results. Finally, it has been shown that the administration of drugs just after endotoxin administration and CLP procedure does not represent medical practice. In the current study, LS was given at $3 \mathrm{~h}$ after CLP, when sepsis seems to be developing 

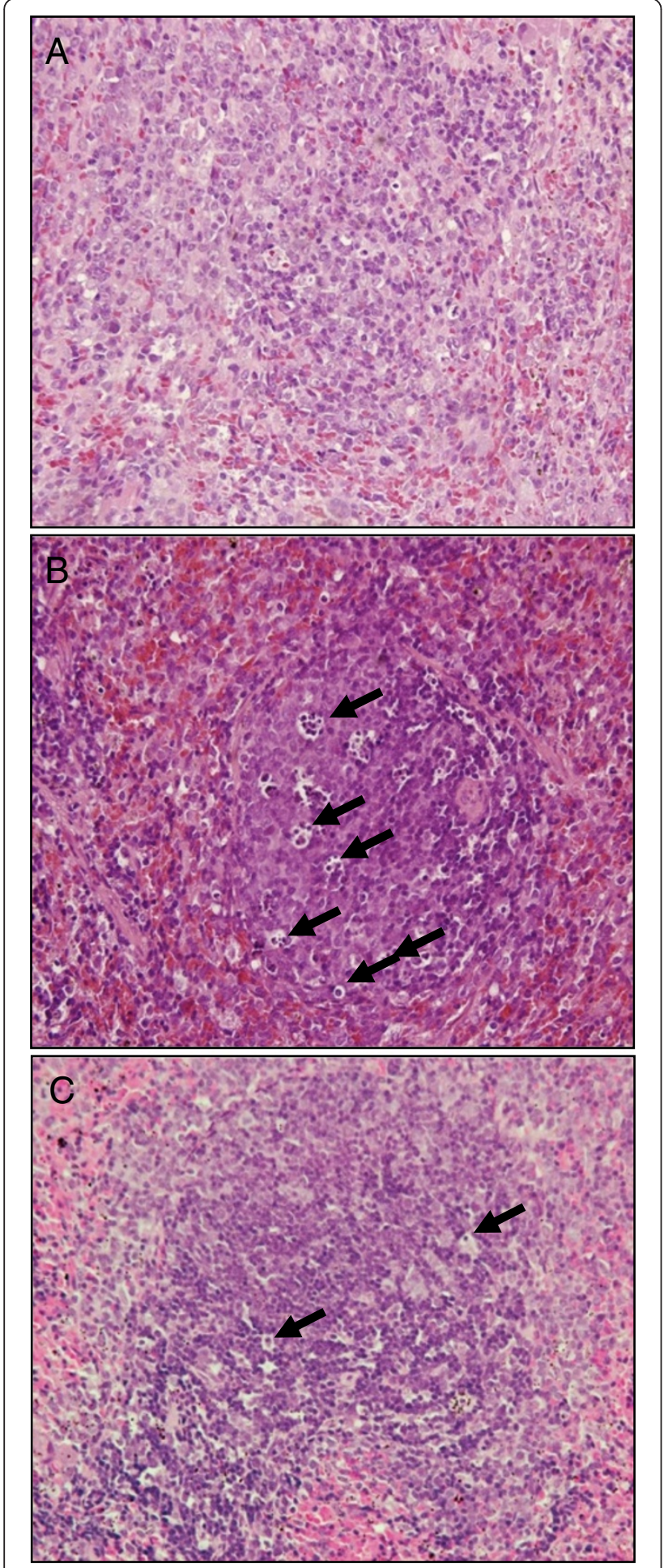

Figure 6 Histopathological studies of spleen. Light microscopy showed spleen sections of rats in groups of (A) sham operation, (B) cecal ligation and puncture, and (C) CLP plus Levosimendan administration. Sections were stained with haematoxylin and eosin. Arrows represent apoptosis in the spleen. Each is shown at $400 \times$ (original magnification).
Table 3 Efffects of Levosimendan (LS) on the survival rate in septic rats duing the pexperimental period

\begin{tabular}{lll}
\hline Groups & Survival rats (\%) \\
\cline { 2 - 3 } & $\mathbf{9} \mathbf{~}$ & $\mathbf{1 8} \mathbf{~}$ \\
\hline SOP & 100 & 100 \\
SOP + LS & 100 & 100 \\
CLP & $64^{*}$ & $40^{*}$ \\
CLP + Veh & $64.7^{*}$ & $41^{*}$ \\
CLP + LS & $71.4^{*}+$ & $61.9^{*}+$ \\
\hline
\end{tabular}

Rats underwent sham operation (SOP, $n=10$ ), SOP and Levosimendan administration ( $S O P+L S, n=6)$, cecal ligation and puncture (CLP, $n=25), C L P$ and vehicle treatment $(C L P+V e h, n=17)$ or CLP and Levosimendan administration $(\mathrm{CLP}+\mathrm{LS}, \mathrm{n}=21) .{ }^{*} P<0.05, \mathrm{CLP}$ versus $\mathrm{SOP} ;{ }^{\dagger} P<0.05, \mathrm{CLP}+\mathrm{LS}$ versus CLP + Veh.

or to have developed. However, the use of LS for a longer period of time after CLP might have different results. Therefore, these results cannot be directly directed to clinical use unless similar interventions have been taken in this sepsis model.

\section{Conclusions}

The present findings support the hypothesis that LS improved survival, minimized histological changes and prevented sepsis-induced multiple organ dysfunction by its anti-inflammatory and anti-apoptosis properties, which involve the inhibition of IL-1 $\beta$ and superoxide production as well as the reduction of iNOS and caspase- 3 expression to the affected tissues. Thus, our present study suggests that a single early dose of LS could be a highly promising agent for protecting tissues from oxidative stress and preventing organ dysfunction due to sepsis, but this hypothesis needs to be proved in further clinical studies.

\section{Key messages}

- Multiple organ dysfunction occurs in rats with peritonitis-induced sepsis

- Levosimendan is protective in the treatment of peritonitis-induced sepsis with respect to survival

- Levosimendan improves haemodynamic variables, reduces organ injury, and attenuates metabolic acidosis in septic rats

- Levosimendan may have anti-inflammatory and anti-apoptosis properties, which involve the inhibition of IL-1 $\beta$ and superoxide production as well as the reduction of iNOS and caspase- 3 expression to the affected tissues

\section{Abbreviations}

ALT: alanine aminotransferase; ANOVA: analysis of variance; AST: aspartate aminotransferase; BUN: blood urea nitrogen; CLP: cecal ligation and puncture; IL-1 $\beta$ : interleukin-1 $\beta$; iNOS: inducible nitric oxide synthase; 
LDH: lactate dehydrogenase; LS: Levosimendan; NO: nitric oxide; PMN: polymorphonuclear neutrophil; SOP: sham of operation; Veh: vehicle.

\section{Competing interests}

The authors declare that they have no competing interests.

\section{Authors' contributions}

CMT planned the research, coordinated the study and drafted the manuscript. KYL performed most of the experiments and analyzed the respective data. SJC participated in the design of the study, performed the statistical analysis and helped to revise the manuscript. SMK carried out the histological experiment and analysis and assisted in manuscript preparation. WJL participated in the sequence alignment and drafted the manuscript. $\mathrm{HCH}$ provided analytic tools, participated in the coordination of the study and critically revised the manuscript. CCW designed and supervised the research and drafted the manuscript. All authors read and approved the final manuscript.

\section{Acknowledgements}

This work was supported by grants from the National Science Council, Taiwan, ROC (NSC 97-2320-B-016-006-MY3, 98-2314-B-075-005-MY3 and 100-2320-B-016-008), Taipei Veterans General Hospital, Taiwan, ROC (VGH-V120C143), and Cheng Hsin General Hospital, Taiwan, ROC (CHGH 100-49).

\section{Author details}

${ }^{1}$ Department of Anesthesiology, Taipei Veterans General Hospital and National Yang-Ming University, Taipei, Taiwan. ${ }^{2}$ Department of Anesthesiology, Tri-Service General Hospital, National Defence Medical Centre, Taipei, Taiwan. ${ }^{3}$ Department of Pharmacology, National Defence Medical Centre, Neihu PO Box 90048-504, Taipei 114, Taiwan. ${ }^{4}$ Department of Nursing, Kang-Ning Junior College of Medical Care and Management, Taipei, Taiwan. ${ }^{5}$ Department of Physiology, National Defence Medical Centre, Taipei, Taiwan. ${ }^{6}$ Graduate Institute of Aerospace and Undersea Medicine, National Defence Medical Centre, Taipei, Taiwan. ${ }^{7}$ Department of Anesthesiology, Tungs' Taichung MetroHarbor Hospital, Taichung, Taiwan. ${ }^{8}$ Department of Anesthesiology, Cheng-Hsin General Hospital, Taipei, Taiwan. ${ }^{9}$ Department of Pharmacology, Taipei Medical University, Taipei, Taiwan. ${ }^{10}$ Department of Anesthesiology and Pain Clinics, Cheng-Hsin Rehabilitation Medical Centre, 45, Cheng-Hsin St, Taipei 112, Taiwan.

Received: 23 May 2014 Accepted: 7 November 2014 Published online: 29 November 2014

\section{References}

1. Ani C, Farshidpanah S, Bellinghausen Stewart A, Nguyen HB: Variations in Organism-Specific Severe Sepsis Mortality in the United States: 1999-2008. Crit Care Med 2014, in press.

2. ProCESS Investigators, Yealy DM, Kellum JA, Huang DT, Barnato AE, Weissfeld LA, Pike F, Terndrup T, Wang HE, Hou PC, LoVecchio F, Filbin MR, Shapiro NI, Angus DC: A randomized trial of protocol-based care for early septic shock. N Engl J Med 2014, 370:1683-1693.

3. Zhou J, Qian C, Zhao M, Yu X, Kang Y, Ma X, Ai Y, Xu Y, Liu D, An Y, Wu D, Sun R, Li S, Hu Z, Cao X, Zhou F, Jiang L, Lin J, Mao E, Qin T, He Z, Zhou L, Du B, China Critical Care Clinical Trials Group (CCCCTG): Epidemiology and outcome of severe sepsis and septic shock in intensive care units in mainland china. PLoS One 2014, 9:e107181.

4. Spronk PE, Zandstra DF, Ince C: Bench-to-bedside review: sepsis is a disease of the microcirculation. Crit Care 2004, 8:462-468.

5. Trzeciak S, Cinel I, Phillip Dellinger R, Shapiro NI, Arnold RC, Parrillo JE, Hollenberg SM, Microcirculatory Alterations in Resuscitation and Shock (MARS) Investigators: Resuscitating the microcirculation in sepsis: the central role of nitric oxide, emerging concepts for novel therapies, and challenges for clinical trials. Acad Emerg Med 2008, 15:399-413.

6. Tsao CM, Chen SJ, Shih MC, Lue WM, Tsou MY, Chen A, Liaw WJ, Wu CC: Effects of terbutaline on circulatory failure and organ dysfunction induced by peritonitis in rats. Intensive Care Med 2010, 36:1571-1578.

7. Haikala H, Kaivola J, Nissinen E, Wall P, Levijoki J, Lindén IB: Cardiac troponin $\mathrm{C}$ as a target protein for a novel calcium sensitizing drug, levosimendan. J Mol Cell Cardiol 1995, 27:1859-1866.
8. Kivikko M, Lehtonen L: Levosimendan: a new inodilatory drug for the treatment of decompendated heart failure. Curr Pharm Des 2005, 11:435-455.

9. Nieminen MS, Fruhwald S, Heunks LM, Suominen PK, Gordon AC, Kivikko M, Pollesello P: Levosimendan: current data, clinical use and future development. Heart Lung Vessel 2013, 5:227-245.

10. Morelli A, Donati A, Ertmer C, Rehberg S, Lange M, Orecchioni A, Cecchini V, Landoni G, Pelaia P, Pietropaoli P, Van Aken H, Teboul JL, Ince C, Westphal M: Levosimendan for resuscitating the microcirculation in patients with septic shocl: a randomized controlled study. Crit Care 2010, 14:R232.

11. Fries M, Ince C, Rossanit R, Bleilevens C, Bickenbach J, Rex S, Mik EG: Levosimendan but not norepinephrine improves microvascular oxygenation during experimental septic shock. Crit Care Med 2008, 36:1886-1891.

12. García-Septien J, Lorente JA, Delgado MA, de Paula M, Nin N, Moscoso A, Sánchez-Ferrer A, Perez-Vizcaino F, Esteban A: Levosimendan increases portal blood flow and attenuates intestinal intramucosal acidosis in experimental septic shock. Shock 2010, 34:275-280.

13. Parissis JT, Adamopoulos S, Antoniades C, Kostakis G, Rigas A, Kyrzopoulos S, \|liodromitis E, Kremastinos D: Effects of levosimendan on circulating pro-inflammatory cytokines and soluble apoptosis mediators in patients with decompensated advanced heart failure. Am J Cardiol 2004, 93:1309-1312.

14. Boost KA, Hoegl S, Dolfen A, Czerwonka H, Scheiermann P, Zwissler B, Hofstetter C: Inhaled levosimendan reduces mortality and release of proinflammatory mediators in a rat model of experimental ventilatorinduced lung injury. Crit Care Med 2008, 36:1873-1879.

15. Zager RA, Johnson AC, Lund S, Hanson SY, Abrass CK: Levosimendan protects against experimental endotoxemic acute renal failure. Am J Physiol Renal Physiol 2006, 290:F1453-F1462.

16. Scheiermann P, Ahluwalia D, Hoegl S, Dolfen A, Revermann M, Zwissler B, Muhl H, Boost KA, Hofstetter C: Effects of intravenous and inhaled levosimendan in severe rodent sepsis. Intensive Care Med 2009, 35:1412-1419.

17. Shih CC, Chen SJ, Chen A, Wu JY, Liaw WJ, Wu CC: Therapeutic effects of hypertonic saline on peritonitis-induced septic shock with multiple organ dysfunction syndrome in rats. Crit Care Med 2008, 36:1864-1872.

18. Yu Z, McNeill JH: Blood pressure and heart rate response to vasoactive agents in conscious diabetic rats. Can J Physiol Pharmacol 1992, 70:1542-1548.

19. Wu JY, Tsou MY, Chen TH, Chen SJ, Tsao CM, Wu CC: Therapeutic effects of melatonin on peritonitis-induced septic shock with multiple organ dysfunction syndrome in rats. J Pineal Res 2008, 45:106-116.

20. Liao MH, Shih CC, Tsao CM, Chen SJ, Wu CC: RhoA/Rho-kinase and nitric oxide in vascular reactivity in rats with endotoxaemia. PLOS One 2013, 8:e56331.

21. Braman RS, Hendrix SA: Nanogram nitrite and nitrate determination in environmental and biological materials by vanadium (III) reduction with chemiluminescence detection. Anal Chem 1989, 61:2715-2718.

22. Tsao CM, Ho ST, Chen A, Wang JJ, Li CY, Tsai SK, Wu CC: Low-dose dexamethasone ameliorates circulatory failure and renal dysfunction in conscious rats with endotoxemia. Shock 2004, 21:484-491.

23. Yu HP, Lui PW, Hwang TL, Yen CH, Lau YT: Propofol improves endothelial dysfunction and attenuates vascular superoxide production in septic rats. Crit Care Med 2006, 34:453-460.

24. Tsao CM, Ho ST, Liaw WJ, Chen A, Wu CC: Combined effects of propofol and dexamethasone on rats with endotoxemia. Crit Care Med 2008, 36:887-894.

25. Javadi P, Buchman TG, Stromberg PE, Husain KD, Dunne WM, Woolsey CA, Turnbull IR, Hotchkiss RS, Karl IE, Coopersmith CM: High-dose exogenous iron following cecal ligation and puncture increases mortality rate in mice and is associated with an increase in gut epithelial and splenic apoptosis. Crit Care Med 2004, 32:1178-1185.

26. Gheorghiade M, Teerlink JR, Mebazaa A: Pharmacology of new agents for acute heart failure syndromes. Am J Cardiol 2005, 96:68G-73G.

27. Hubbard WJ, Choudhry M, Schwacha MG, Kerby JD, Rue LW 3rd, Bland KI, Chaudry $\mathrm{IH}$ : Cecal ligation and puncture. Shock 2005, 24:52-57.

28. Wen H: Sepsis induced by cecal ligation and puncture. Methods Mol Biol 2013, 1031:117-124.

29. Zingarelli B, Day BJ, Crapo JD, Salzman AL, Szabó C: The potential role of peroxynitrite in the vascular contractile and cellular energetic failure in endotoxic shock. Br J Pharmacol 1997, 120:259-267. 
30. Takakura K, Taniguchi T, Muramatsu I, Takeuchi K, Fukuda S: Modification of alpha1-adrenoceptors by peroxynitrite as a possible mechanism of systemic hypotension in sepsis. Crit Care Med 2002, 30:894-899.

31. Kimmoun A, Ducrocq N, Levy B: Mechanisms of vascular hyporesponsiveness in septic shock. Curr Vasc Pharmacol 2013, 11:139-149.

32. Alvarez S, Evelson PA: Nitric oxide and oxygen metabolism in inflammatory conditions: sepsis and exposition to polluted ambients. Front Biosci 2007, 12:964-974.

33. Hotchkiss RS, Nicholson DW: Apoptosis and caspases regulate death and inflammation in sepsis. Nat Rev Immunol 2006, 6:813-822.

34. Wesche-Soldato DE, Swan RZ, Chung CS, Ayala A: The apoptotic pathway as a therapeutic target in sepsis. Curr Drug Targets 2007, 8:493-500.

35. Boatright KM, Salvesen GS: Mechanisms of caspase activation. Curr Opin Cell Biol 2003, 15:725-731.

36. Plaschke K, Bent F, Wagner S, Zorn M, Kopitz J: In contrast to its antiinflammatory and anti-apoptotic peripheral effect, levosimendan failed to induce a long-term neuroprotective effect in a rat model of mild septic encephalopathy: a pilot study. Neurosci Lett 2014, 560:117-121.

37. Jaeschke $H$, Hasegawa $\mathrm{T}$ : Role of neutrophils in acute inflammatory liver injury. Liver Int 2006, 26:912-919.

38. Torraco A, Carrozzo R, Piemonte F, Pastore A, Tozzi G, Verrigni D, Assenza M, Orecchioni A, D'Egidio A, Marraffa E, Landoni G, Bertini E, Morelli A: Effects of levosimendan on mitochondrial function in patients with septic shock: A randomized trial. Biochimie 2014, 102:166-173.

39. Mythen MG, Webb AR: Intra-operative gut mucosal hypoperfusion is associated with increased postoperative complications and cost. Intensive Care Med 1994, 20:99-104.

40. Pagel PS, Hettrick DA, Warltier DC: Influence of levosimendan, pimobendan, and milrinone on the regional distribution of cardiac output in anaesthetized dogs. Br J Pharmacol 1996, 119:609-615.

41. Schwarte LA, Picker O, Bornstein SR, Fournell A, Scheeren TW: Levosimendan is superior to milrinone and dobutamine in selectively increasing microvascular gastric mucosal oxygenation in dogs. Crit Care Med 2005, 33:135-142.

42. Memiş $\mathrm{D}$, Inal MT, Sut N: The effects of levosimendan vs dobutamine added to dopamine on liver functions assessed with noninvasive liver function monitoring in patients with septic shock. J Crit Care 2012 27:318. e1-6.

43. Kopustinskiene DM, Pollesello P, Saris NE: Potassium-specific effects of levosimendan on heart mitochondria. Biochem Pharmacol 2004, 68:807-812.

44. Szilagyi S, Pollesello P, Levijoki J, Kaheinen P, Haikala H, Edes I, Papp Z: The effects of levosimendan and OR-1896 on isolated hearts, myocyte-sized preparations and phosphodiesterase enzymes of the guinea pig. Eur J Pharmacol 2004, 486:67-74.

doi:10.1186/s13054-014-0652-4

Cite this article as: Tsao et al.: Levosimendan attenuates multiple organ injury and improves survival in peritonitis-induced septic shock: studies in a rat model. Critical Care 2014 18:652.

\section{Submit your next manuscript to BioMed Central and take full advantage of:}

- Convenient online submission

- Thorough peer review

- No space constraints or color figure charges

- Immediate publication on acceptance

- Inclusion in PubMed, CAS, Scopus and Google Scholar

- Research which is freely available for redistribution

Submit your manuscript at www.biomedcentral.com/submit
Ciomed Central 